\title{
A Simple Method for Anchoring Silver and Copper Nanoparticles on Single Wall Carbon Nanotubes
}

\author{
Mariana M. Silva $\left.{ }^{1}{ }^{(}\right)$, Daniel Ribeiro ${ }^{1}$, Eunice Cunha $\left.{ }^{2}{ }^{(}\right)$, M. Fernanda Proença ${ }^{3}$, \\ Robert J. Young ${ }^{2}(\mathbb{D}$ and Maria C. Paiva $1, * \mathbb{D}$ \\ 1 Institute for Polymers and Composites, University of Minho-Campus of Azurém, 4800-058 Guimarães, \\ Portugal; b8523@dep.uminho.pt (M.M.S.); daniel.ribeiro@dep.uminho.pt (D.R.) \\ 2 National Graphene Institute and School of Materials, University of Manchester, Manchester M13 9PL, UK; \\ eunice.cunha-2@manchester.ac.uk (E.C.); robert.young@manchester.ac.uk (R.J.Y.) \\ 3 Centre of Chemistry, University of Minho-Campus of Gualtar, 4710-057 Braga, Portugal; \\ fproenca@quimica.uminho.pt \\ * Correspondence: mcpaiva@dep.uminho.pt
}

Received: 11 September 2019; Accepted: 1 October 2019; Published: 4 October 2019

check for updates

\begin{abstract}
Single walled carbon nanotubes (SWCNT) were functionalized using the 1,3-dipolar cycloaddition reaction of an azomethine ylide under solvent-free conditions, a one-pot procedure that yields pyrrolidine type of groups at the nanotubes surface. The functionalized SWCNT were further decorated with $\mathrm{Ag}$ and $\mathrm{Cu}$ nanoparticles by reduction of the corresponding metal salts in dimethylformamide. The extensive reduction of silver from its nitrate was observed, as well as the partial reduction of copper from its acetate. X-ray photoelectron spectroscopy (XPS) confirmed the functionalization of SWCNT with pyrrolidine that provided anchoring sites for the metal nanoparticles. Metal nanoparticles (NP) were formed at the surface of the organically functionalized SWCNT in higher yields as compared to the same procedure carried out with pristine SWCNT. This was observed using scanning electron microscopy (SEM) and quantified by XPS. Raman spectroscopy demonstrated that functionalization and metal decoration of the SWCNT did not induce structural damage to the SWCNT.
\end{abstract}

Keywords: 1,3-dipolar cycloaddition; functionalization of SWCNT; metal anchoring

\section{Introduction}

Outstanding properties have been attributed to single walled carbon nanotubes (SWCNT) [1-11] since their discovery by Iijima [12]. The chemical inertia of carbon nanotubes (CNT), however, limits their application and much work has been undertaken in the field of non-covalent and covalent functionalization in attempts to increase their solubility or improve their interfacial bonding with different matrix materials. The underlying inertia comes from the tight $\mathrm{sp}^{2}$ bonds of the hexagonal carbon lattice as well as the stable tubular structure and strong van der Waals interactions that hold the tubes together in bundles. The reactivity of SWCNT is higher at the end caps due the curvature of the C-C network, at Stone-Wales defects [13], and for smaller diameter SWCNT, also due to curvature effects [14]. Noncovalent and covalent modifications as well as decoration with metal nanoparticles are strategies that were applied to fulfil the purpose of increased solubility, for the exploitation of the SWCNT properties and their reactivity, to develop hybrid materials for several applications $[15,16]$.

Georgakilas et al. [17] described the 1,3-dipolar cycloaddition (DCA) of azomethine ylides to the surface of SWCNT, a reaction adapted from previous studies with fullerenes [18]. Since then a series of 1,3-dipolar cycloadditions of azomethine ylides to SWCNT has been reported [17,19-27] using Prato's reaction route as well as microwave assisted synthesis. DCA reactions are expected to be less 
damaging for CNT than fluorination and oxidation reactions, thus minimizing the defects inflicted by functionalization while enhancing the reactivity of the CNT surface. Nevertheless, these reactions can be time consuming (several days, when carried out in solution) and are hardly scalable. Paiva et al. reported the DCA of azomethine ylides to the surface of multi wall CNT (MWCNT) [28] and carbon nanofibers [29] through a simple and scalable one-pot solvent free method.

Frequently, the cycloaddition reactions reported in the literature for SWCNT require prior purification $[19,21-23,25]$, since commercially available SWCNT contain impurities such as amorphous carbon and metal catalysts that may affect the chemical reactions. The reagents used to modify the surface of SWCNT can functionalize other carbonaceous materials present, as well as complex with residual catalyst, thus reducing the extent of surface functionalization of the CNT.

The reduction of $\mathrm{Ag}$ and $\mathrm{Cu}$ salts to their elemental form has been studied and was successfully achieved using different approaches, such as described in the literature for the production of metal decorated SWCNT, with Ag [30-35] and $\mathrm{Cu}[36,37]$. Dimethylformamide (DMF) is commonly used as a solvent, however this amide may be used as a reducing agent for some metal salts. The preparation of Ag nanoparticles (NP) by reduction of $\mathrm{AgNO}_{3}$ in DMF is described in the literature [38] and has been used as a route for decorating MWCNT [39,40] and graphene oxide [41], however with limited efficiency in the absence of anchoring sites along the CNT surface. Sulfur and amine groups attached to the side wall of CNT were observed to be potential stabilizers of cations, as previously reported by Ma et al. [40], acting as anchoring sites for Ag NP.

Hybrid CNT/metal NP are of interest in applications such as sensing [30,36,42,43], energy storage [31], health monitoring [44], supercapacitors [45] as well as transistors and memory devices [46]. However, in spite of the excellent properties of SWCNT, their effective transfer to the final application is hindered by the presence of SWCNT bundles, structural defects, and conductivity variation with nanotube chirality, etc. Moreover, their contact resistance with metals poses a potential problem to device performance, and this has been the focus of several studies [47,48]. The modification of the inter-nanotube bundles by metal nanoparticle decoration to produce hybrid networks has shown potential for the reduction of contact resistance between the nanotubes [49], which is interesting for the above-mentioned applications. Another potential application for hybrid SWCNT/metal NP is the preparation of substrates for surface-enhanced Raman scattering (SERS) [50,51]. It was demonstrated that the SWCNT Raman response can be considerably enhanced by the attachment of metallic NP [50]. Attaching Ag NP to the surface of SWCNT was also used for the assembly of active surfaces for a label-free detection of ssDNA [30] and $\mathrm{Cu} N P$ were applied for enhancing the sensitivity of a $\mathrm{H}_{2} \mathrm{~S}$ sensor [36].

In the present study we report the organic functionalization of SWCNT using the solvent-free 1,3-dipolar cycloaddition of an azomethine ylide, adapted from the MWCNT functionalization method proposed by Paiva et al. [29]. The outcome of the functionalization on pristine and purified SWCNT was evaluated. Furthermore, the functionalized SWCNT (f-SWCNT) were decorated with Ag and $\mathrm{Cu}$ nanoparticles through the reduction of $\mathrm{AgNO}_{3}$ and $\mathrm{Cu}\left(\mathrm{CH}_{3} \mathrm{COO}\right)_{2}$ in DMF in the presence of suspended f-SWCNT, yielding hybrid SWCNT (h-SWCNT). The functionalized and hybrid materials were analyzed by X-ray photoelectron spectroscopy (XPS), Raman spectroscopy, thermogravimetric analysis (TGA), and scanning electron microscopy with energy dispersive spectroscopy (EDS) analysis, demonstrating the effectiveness of this simple methodology to synthetize h-SWCNT.

\section{Materials and Methods}

\subsection{Purification of the SWCNT}

SWCNT Tuball ${ }^{\mathrm{TM}}$ were purchased from OCSiAl Ltd. (Luxembourg, Batch 109-16092015). The chemical purification process was adapted from the procedures proposed by Wang et al. [52] and Clancy et al. [53]. SWCNT powder $(25 \mathrm{mg})$ was stirred in a mixture of $\mathrm{HCl}(1 \mathrm{M}, 25 \mathrm{~mL})$ and $\mathrm{H}_{2} \mathrm{O}_{2}$ $(30 \% \mathrm{wt} / \mathrm{wt}, 25 \mathrm{~mL})$, from Fisher Scientific (UK), and heated at $60^{\circ} \mathrm{C}$. After each hour, $25 \mathrm{~mL}$ of both 
reactants were added for a total of $4 \mathrm{~h}$. Vacuum filtration was carried out with a Nylon membrane (GE Healthcare, IL, USA, Whatman ${ }^{\mathrm{TM}}, 0.45 \mu \mathrm{m}$ pore size) and the filtrate was washed with deionized water until the $\mathrm{pH}$ of the filtration liquid reached seven.

\subsection{Functionalization of Pristine and Purified SWCNT}

The functionalization procedure of the SWCNT was carried out using the solvent-free DCA reaction. The alfa amino acid and aldehyde used were N-benzyloxycarbonylglycine (Z-Gly-OH) and paraformaldehyde (PFA), respectively (both acquired from ACROS Organics, Belgium, with $>96 \%$ purity). The procedure was adapted from that described in the literature for nanofibers [28] and MWCNT [29]. This procedure was adjusted for the functionalization of SWCNT considering their larger surface area and higher curvature compared to MWCNT. Two different ratios of SWCNT to Z-Gly-OH were tested. The reaction conditions employed are described in Table 1.

Table 1. Compositions of single walled carbon nanotubes (SWCNT), N-benzyloxycarbonylglycine (Z-Gly-OH), and paraformaldehyde (PFA) used for the 1,3-dipolar cycloaddition reaction.

\begin{tabular}{cccccc}
\hline Sample & SWCNT & SWCNT:Z-Gly-OH & Z-Gly-OH:PFA & Temperature $\left({ }^{\circ} \mathrm{C}\right)$ & Reaction Time (h) \\
\hline f-S1 ${ }^{1}$ & Pristine & $1: 1(\mathrm{wt})$ & & $230 \pm 10$ & \\
f-S6 & Pristine & $1: 6(\mathrm{wt})$ & $1: 6(\mathrm{~mol})$ & $230 \pm 15$ & 2 \\
f-SP1 & Purified & $1: 1(\mathrm{wt})$ & $250 \pm 13$ & \\
\hline \multicolumn{5}{c}{ ' Sample used for the decoration with metal nanoparticles (NP). }
\end{tabular}

The reaction products were filtered through a qualitative filter, 25-30 $\mu \mathrm{m}$ pore size (Prat Dumas, France), and washed with a sequence of solvents, namely hexane, ethanol, and acetone (from Fisher Scientific, UK). The functionalized pristine SWCNT (f-S1 and f-S6, with ratios of 1:1 and 1:6 of SWCNT to Z-Gly-OH, respectively) were dried at $150{ }^{\circ} \mathrm{C}$ for $1 \mathrm{~h}$ under vacuum and the purified SWCNT were dried at $200{ }^{\circ} \mathrm{C}$ (f-SP1). A buckypaper-like structure (tightly packed SWCNT bundles) was obtained for all samples.

\subsection{Decoration of SWCNT with Metal Salts}

Decoration with $\mathrm{Ag}$ and $\mathrm{Cu}$ was based on the reduction of $\mathrm{AgNO}_{3}$ and $\mathrm{Cu}\left(\mathrm{CH}_{3} \mathrm{COO}\right)_{2}$ in DMF. f-SWCNT (f-S1, $70 \mathrm{mg}$ ) were dispersed in $4 \mathrm{~mL}$ of DMF (Panreac) and magnetic stirred for $15 \mathrm{~min}$. Mixtures of $35 \mathrm{mg}$ of copper acetate $\left(\mathrm{Cu}\left(\mathrm{CH}_{3} \mathrm{COO}\right)_{2}\right.$, Alfa Aesar, MA, USA) in $2 \mathrm{~mL}$ of EtOH (Fischer Scientific, UK) and $35 \mathrm{mg}$ of silver nitrate $\left(\mathrm{AgNO}_{3}\right.$, from Fischer Scientific, UK) in $2 \mathrm{~mL}$ of EtOH were kept under magnetic stirring for $15 \mathrm{~min}$ and mixed with two separate suspensions of f-SWCNT in DMF. The mixtures were stirred for $78 \mathrm{~h}$ with an ultra-sonication step (10 min, ultrasonic bath) every $24 \mathrm{~h}$. The reaction flasks were covered with aluminum foil throughout the procedure. Reaction products were filtered and washed with hexane followed by diethyl ether (Fischer Scientific, UK). Filtration and washing were carried out over a nylon membrane yielding SWCNT buckypapers.

\subsection{Characterization of the SWCNT}

\subsubsection{Scanning Electron Microscopy and Energy-Dispersive X-ray Spectroscopy}

Scanning electron microscopy (SEM), electron backscatter diffraction (EBSD) images and EDS spectra were obtained with a Nano SEM-FEI Nova 200 (FEG/SEM) with an integrated EDAX-Pegasus $\mathrm{X} 4 \mathrm{M}$ at high vacuum (1.0 $\mathrm{nm}$ at $15 \mathrm{kV}$ resolution). An SUTW, Sapphire detector was used for EDS.

\subsubsection{Thermogravimetric Analysis}

TGA measurements were performed on a TGA Q500 from T.A. Instruments ${ }^{\circledR}$ (weighting precision of $\pm 0.01 \%, 0.1 \mu \mathrm{g}$ sensitivity) at a heating rate of $10^{\circ} \mathrm{C} / \mathrm{min}$ from $40^{\circ} \mathrm{C}$ to $700{ }^{\circ} \mathrm{C}$ or $800{ }^{\circ} \mathrm{C}$, under $\mathrm{N}_{2}$ atmosphere, and a rate of $10{ }^{\circ} \mathrm{C} / \mathrm{min}$ from $40{ }^{\circ} \mathrm{C}$ to $800{ }^{\circ} \mathrm{C}$ under $\mathrm{O}_{2}$ atmosphere, in a platinum crucible. 


\subsubsection{X-ray Photoelectron Spectroscopy}

XPS spectra were acquired with a Kratos Axis Ultra Hybrid with an $\mathrm{Al} \mathrm{K \alpha}$ monochromated X-ray source $(1486.6 \mathrm{eV})$ with a sampling depth between 3-10 nm. XPS spectra were analyzed recurring to CasaXPS software. All spectra were calibrated relative to $\mathrm{C} 1 \mathrm{~s}$ major peak fit at $284.8 \mathrm{eV}$ ( $\mathrm{C}=\mathrm{C}$ bond). The $\mathrm{C} 1$ s peak was fitted firstly with an asymmetrical peak at $\sim 284.8 \mathrm{eV}$, attributed to $\mathrm{C}=\mathrm{C}$ bonds. A wide peak at $\sim 291 \mathrm{eV}$ is attributed to $\pi-\pi$ interactions, a non-covalent interaction of the conjugated pi-systems, in this case no FWHM nor area constraints were applied. A Gaussian function and FWHM constriction of $\mathrm{C}=\mathrm{C} F W H M \times 1$ in relation to the higher intensity peak fit was used as well for other 1s peaks.

\subsubsection{Raman Spectroscopy}

Raman spectra were obtained using a HORIBA LabRAM HR Evolution equipped with a $532 \mathrm{~nm}$ laser. The Raman spectrometer is coupled to a CCD detector (Horiba) and a microscope equipped with a $100 \times$ magnification objective. A grating of $1800 \mathrm{gr} / \mathrm{mm}$ was used to obtain high spectral resolution. For each sample, three spectra were recorded and averaged, peak area and maximum were determined by the application of a polynomial baseline and fitting with a Lorentzian function.

Spectra in the radial breathing mode (RBM) range were acquired with a $532 \mathrm{~nm}$ laser with $900 \mathrm{gr} / \mathrm{mm}, 100 \% \mathrm{ND}$ filter, $10 \mathrm{~s}$ acquisition time and four accumulations in the range of 100 to $500 \mathrm{~cm}^{-1}$. From the mappings two representative spectra were selected for each sample.

\section{Results and Discussion}

The organic functionalization studies were carried out upon SWCNT with the nanotubes purified using a method proposed in the literature [49]. The pristine and purified SWCNT were functionalized via DCA reaction, using a procedure adapted from that previously described for the functionalization of multiwall carbon nanotubes [29]. The reaction scheme is presented in Figure 1, showing the formation of the reactive dipole by heating paraformaldehyde and $\mathrm{Z}-\mathrm{Gly}-\mathrm{OH}$, and its reaction products on the SWCNT wall. The DCA reaction was carried out varying the Z-Gly-OH content and the reaction temperature, and the functionalization yield was evaluated by XPS analysis. Finally, the decoration of the f-SWCNT with metal NP via reduction of the metal salts in DMF and anchoring on the nanotubes was carried out.

(a)<smiles>NCCC(=O)O</smiles><smiles>O=CCOCCO</smiles>
$\mathrm{R}=-\mathrm{COOCH}_{2} \mathrm{Ph}$

$-\mathrm{H}_{2} \mathrm{O}$

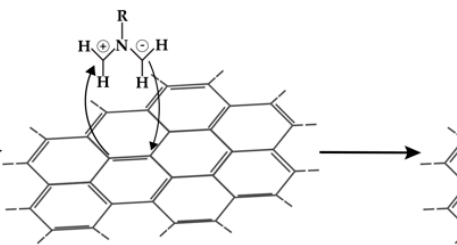

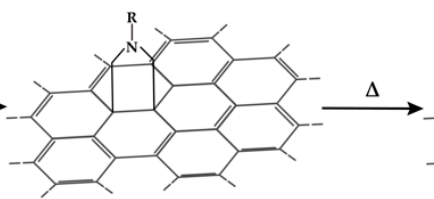

1

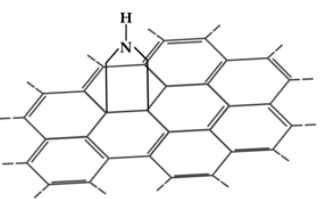

2

(b)

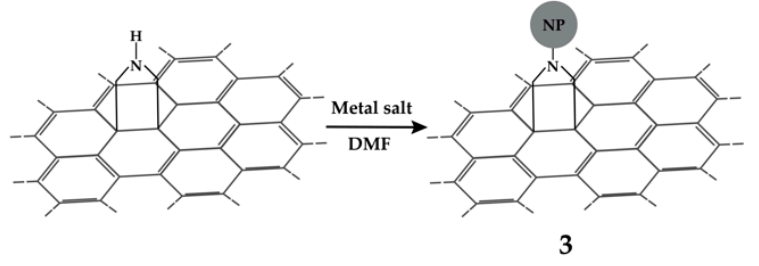

Figure 1. Schematics of the reactions carried out: (a) 1,3-dipolar cycloaddition (DCA) reaction, where 1 and 2 are the products; (b) anchoring of metal nanoparticles (product 3 ) on the pyrrolidine groups formed by the DCA reaction.

\subsection{Scanning Electron Microscopy}

Figure 2 illustrates the morphology of the SWCNT after each step of chemical modification. The SEM images show the structural integrity of the SWCNT after purification and functionalization. 
(a)

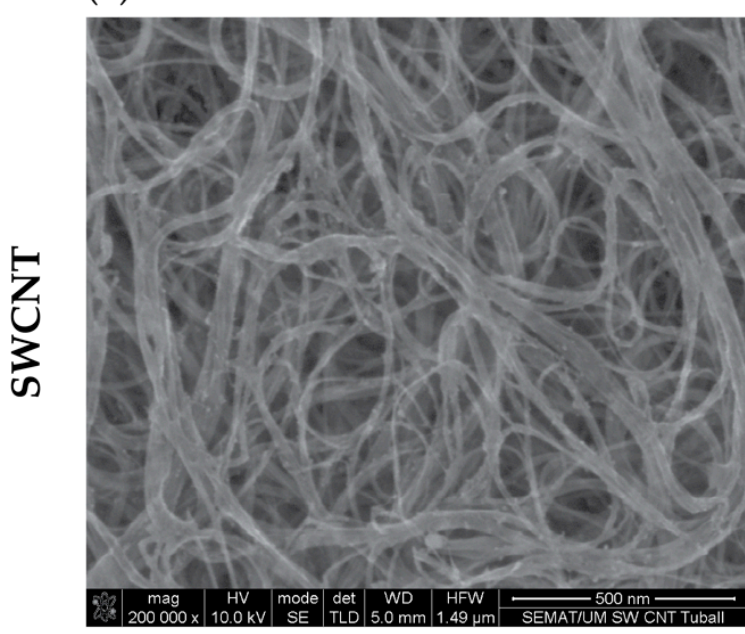

(c)

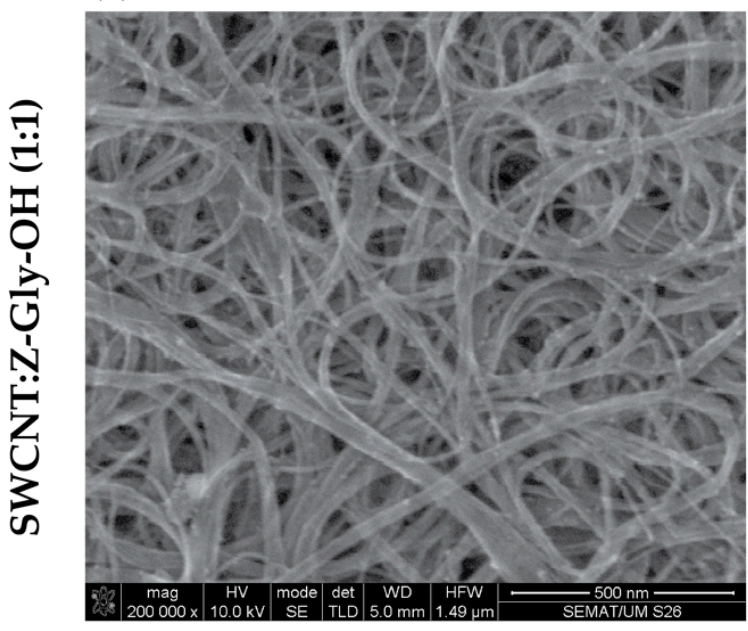

(e)

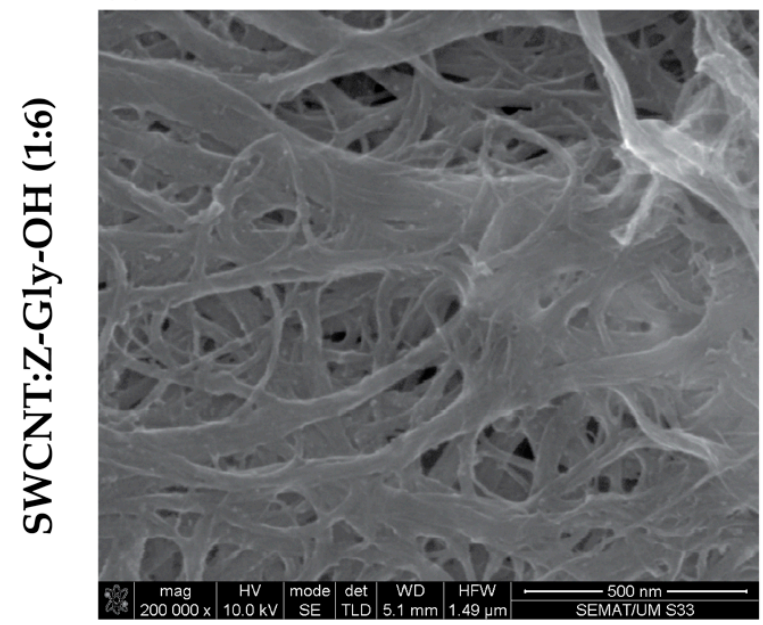

(b) $\quad$ SP (purified)

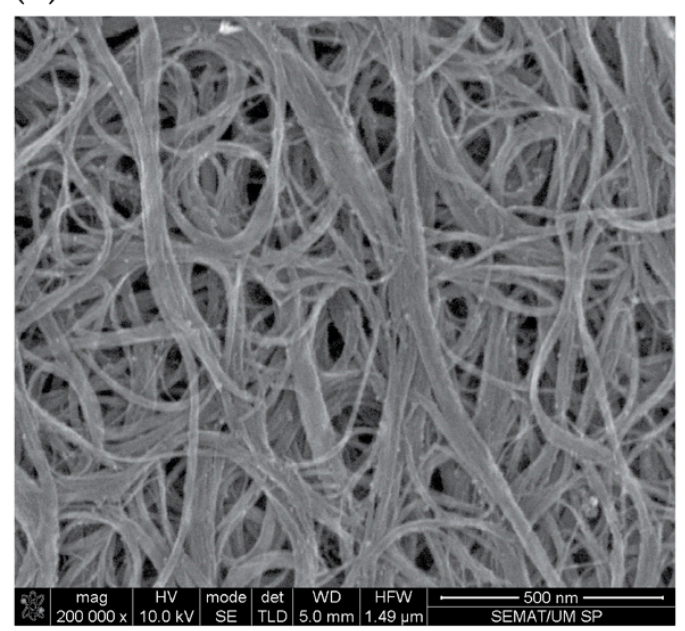

(d)

$\mathrm{f}-\mathrm{SP} 1\left(\mathrm{~T} \sim 250^{\circ} \mathrm{C}\right)$

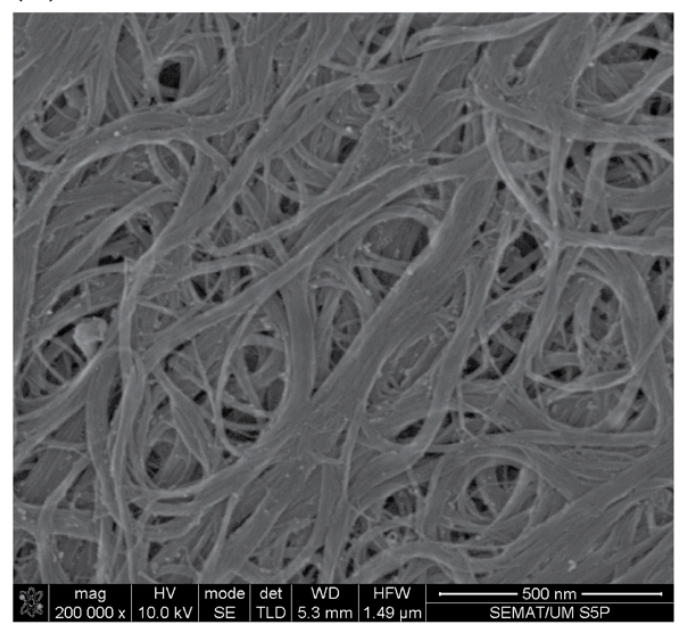

Figure 2. SEM micrographs of the (a) pristine, (b) purified, and (c-e) functionalized SWCNT.

Figure 3 illustrates the higher yield of NP formation and anchoring on the f-SWCNT relative to the same procedure performed on pristine SWCNT. This was particularly clear for Ag NP whereas $\mathrm{Cu}$ NP were observed to form large clusters (albeit nano-sized). The EDS spectra demonstrates the 
presence of nitrogen-containing groups as well as $\mathrm{Cu}$ and $\mathrm{Ag}$ in metal form. EDS is a local surface measurement that may be used in combination with SEM to estimate the metal NP size. However, the measurements are difficult to perform due to the small size of the metal nanoparticles and the interference of the Fe catalyst. Images highlighting the distribution of Fe and Ag separately are shown in the supplementary materials (Figure S1b,c). Quantitative analysis of the overall Fe, $\mathrm{Ag}$, and Cu contents were performed for the functionalized and decorated samples using TGA.
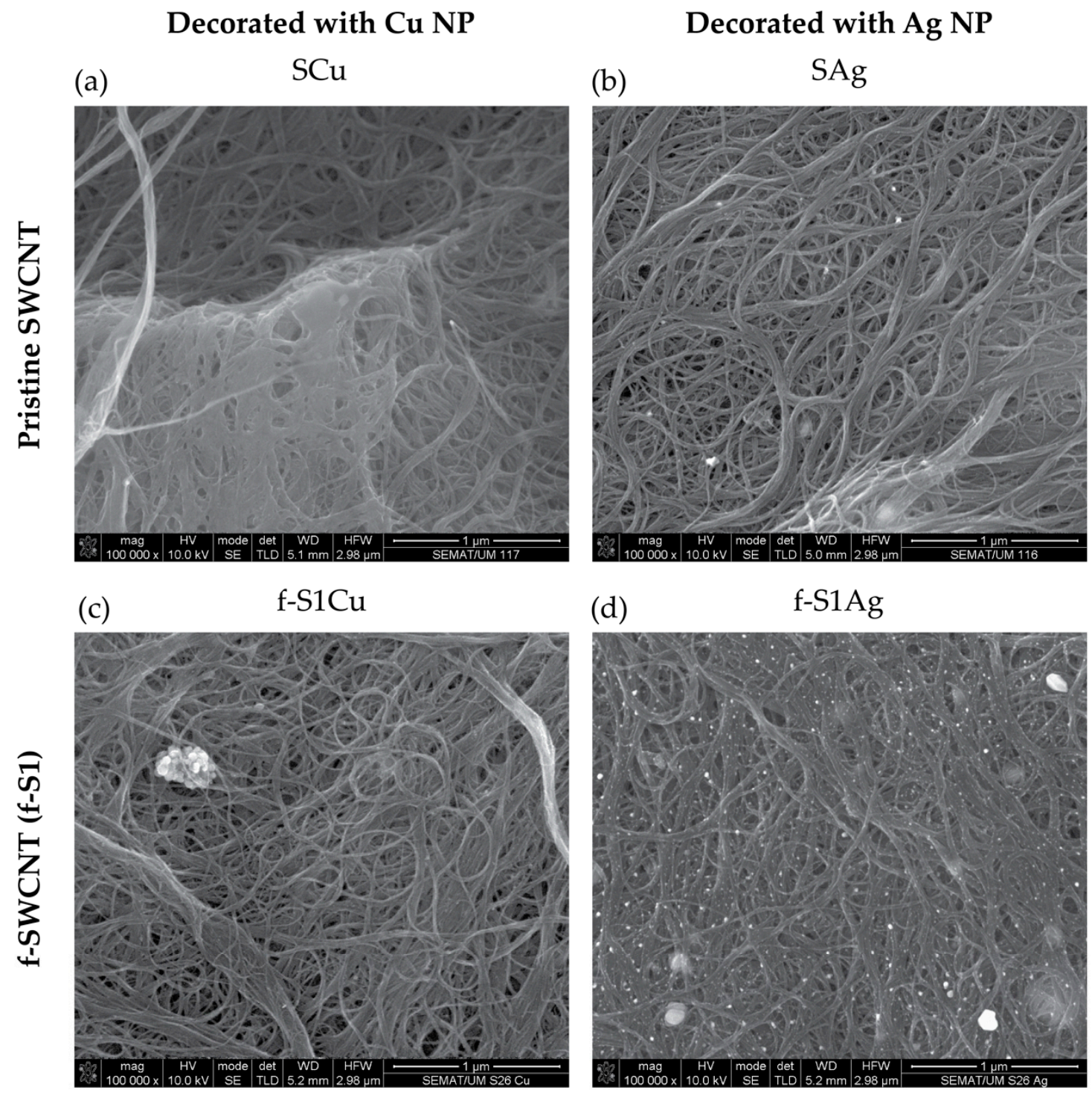

\begin{tabular}{|ccccc|}
\hline \multicolumn{5}{c|}{ EDS elemental analysis (at\%) } \\
& SCu & f-S1Cu & SAg & f-S1Ag \\
C K & 93.70 & 82.66 & 91.22 & 76.28 \\
O K & 3.83 & 4.96 & 3.63 & 6.21 \\
N K & - & 10.60 & - & 1.99 \\
Cu K & 0.27 & 0.35 & - & - \\
Ag L & - & - & 2.12 & 3.90 \\
\hline
\end{tabular}

Figure 3. SEM images of the SWCNT, $(\mathbf{a}, \mathbf{b})$ pristine and $(\mathbf{c}, \mathbf{d})$ functionalized, after reduction of metal $\mathrm{NP}$ in dimethylformamide (DMF), and (e) corresponding energy dispersive spectroscopy (EDS) results. 


\subsection{Functionalization of the SWCNT}

SWCNT may be heated to temperatures above $2000^{\circ} \mathrm{C}$ under inert atmosphere without significant weight loss and keeping their structural integrity. Thus, the weight loss observed during TGA testing under inert atmosphere may be attributed to loss of the organic functionalization of the SWCNT. Organic compounds typically decompose above $180-200{ }^{\circ} \mathrm{C}$ yielding volatile products and thus undergoing weight loss. Figure 4a shows normalized TGA curves for the SWCNT and f-SWCNT under an $\mathrm{N}_{2}$ atmosphere, showing mass loss up to $21.85 \%$. Thermal decomposition occurs through at least two degradation steps starting above $150{ }^{\circ} \mathrm{C}$ and extending up to $500{ }^{\circ} \mathrm{C}$. Considering the scheme in Figure 1 the major degradation steps may be assigned to cleavage of the R group in 1 and decomposition of the remaining pyrrolidine group in 2. Comparing the TGA curves for f-S1 and f-SP1 (the SWCNT that were functionalized with similar reagent ratios but different reaction temperature) a larger overall weight loss is observed for $\mathrm{f}-\mathrm{S} 1$ indicating that, if similar functionalization yield was achieved, $\mathrm{f}-\mathrm{S} 1$ is functionalized with a larger fraction of $>\mathrm{NR}$ (product 1 in Figure 1) compared to f-SP1. Table 2 shows that the overall weight loss was much lower for f-SP1 compared to the other f-SWCNT, which is consistent with a larger contribution of the "lighter" group 2 in f-SP1. f-S6 was produced using a large excess of amino acid, showing what appears to be a large organic layer by SEM, however presenting an overall weight loss similar to that of f-S1. The major degradation step occurs near $400{ }^{\circ} \mathrm{C}$ which is consistent with the presence of a stable pyrrolidine group.

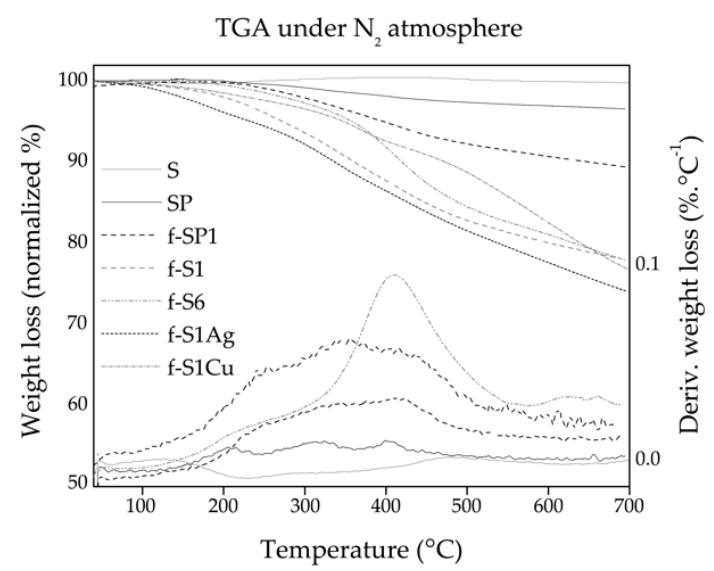

(a)

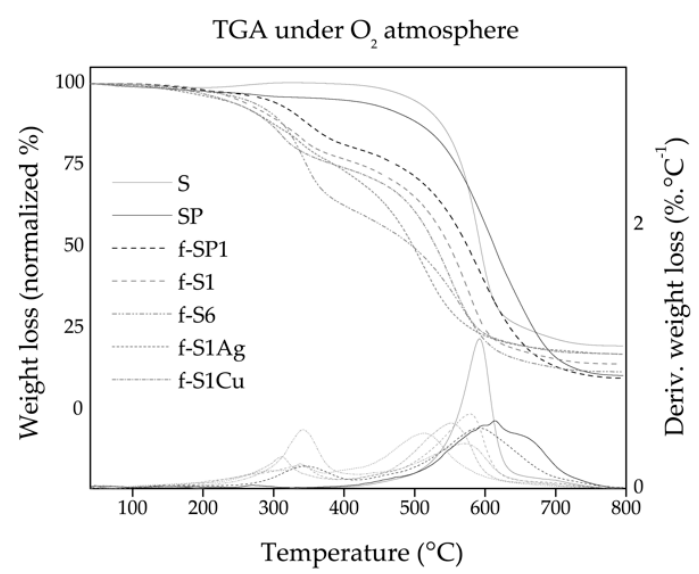

(b)

Figure 4. Normalized thermogravimetric analysis (TGA) curves and corresponding derivative: (a) under $\mathrm{N}_{2}$ atmosphere for pristine, purified and functionalized SWCNT (f-SWCNT); (b) pristine, purified, f-SWCNT, and hybrid SWCNT (h-SWCNT), under $\mathrm{O}_{2}$ atmosphere.

Heating under $\mathrm{O}_{2}$ all organic carbon undergoes burn-off below $600{ }^{\circ} \mathrm{C}$, leaving only inorganic matter and metals/oxidized metals. For SWCNT and functionalized SWCNT, the residue formed corresponds mostly to iron oxide for pristine, purified, and f-SWCNT, and iron, silver, or copper oxides for h-SWCNT. The oxidative degradation TGA curves for pristine SWCNT (S), f-SWCNT (f-S1) and corresponding h-SWCNT (f-S1Ag and f-S1Cu) is shown in Figure 4b. Thermal-oxidative degradation initiates above $250{ }^{\circ} \mathrm{C}$ for all functionalized materials showing the larger degradation step above $500{ }^{\circ} \mathrm{C}$. Pristine SWCNT are characterized by an incipient weight gain above $200{ }^{\circ} \mathrm{C}$ due to oxidative processes, and a steep decomposition step near $500^{\circ} \mathrm{C}$. The temperature of maximum degradation rate of SP (peak temperature for the first derivative of the TGA curve), listed in Table 2, is shifted to higher temperature by approximately $20^{\circ} \mathrm{C}$ as compared to as-received SWCNT (S), confirming the effectiveness of the purification process. The f-SWCNT show in general a weight loss starting at lower temperature due to the thermal degradation of the organic groups bonded to their sidewalls. 
Table 2. TGA results for the analysis performed under nitrogen and under oxygen atmosphere.

\begin{tabular}{|c|c|c|c|c|}
\hline \multirow{3}{*}{ Sample } & \multicolumn{4}{|c|}{ In Nitrogen } \\
\hline & \multicolumn{2}{|c|}{ 1st Derivative peak $\mathrm{T}\left({ }^{\circ} \mathrm{C}\right)$} & \multirow{2}{*}{$\begin{array}{l}\text { Weight loss (wt.\%) } \\
@ 0700{ }^{\circ} \mathrm{C}\end{array}$} & \multirow{2}{*}{$\begin{array}{c}\text { Approx. residue from } \mathrm{Cu} \text { or } \\
\mathrm{Ag} \text { anchoring }\end{array}$} \\
\hline & T1 & $\mathrm{T} 2$ & & \\
\hline S & - & - & 0.19 & - \\
\hline SP & - & - & 5.09 & - \\
\hline f-S6 & 200 & 409 & 22.04 & - \\
\hline f-SP1 & 240 & 345 & 14.74 & - \\
\hline $\mathrm{f}-\mathrm{S} 1$ & 175 & 335 & 21.72 & - \\
\hline $\mathrm{f}-\mathrm{S} 1 \mathrm{Cu}$ & 203 & 367 & 16.95 & 4.8 \\
\hline \multirow[t]{4}{*}{ f-S1Ag } & 170 & 331 & 15.06 & 6.7 \\
\hline & \multicolumn{4}{|c|}{ In Oxygen } \\
\hline & \multicolumn{2}{|c|}{ 1st Derivative peak T $\left({ }^{\circ} \mathrm{C}\right)$} & \multirow{2}{*}{ Fe (wt.\%) } & \multirow{2}{*}{$\begin{array}{l}\text { Residual weight (wt.\%) } \\
@ 800{ }^{\circ} \mathrm{C}\end{array}$} \\
\hline & T1 & $\mathrm{T} 2$ & & \\
\hline $\mathrm{S}$ & - & 592 & 13.7 & 19.64 \\
\hline SP & 269 & 614 & 10.9 & 15.53 \\
\hline f-S6 & 341 & 572 & 8.3 & 11.81 \\
\hline f-SP1 & 344 & 593 & 6.7 & 9.64 \\
\hline $\mathrm{f}-\mathrm{S} 1$ & 338 & 578 & 10.0 & 14.35 \\
\hline $\mathrm{f}-\mathrm{S} 1 \mathrm{Cu}$ & 311 & 552 & $\sim 10.0$ & 17.5 \\
\hline f-S1Ag & 337 & 515 & $\sim 10.0$ & 17.7 \\
\hline
\end{tabular}

The Fe content was estimated from the weight $\%$ residue obtained under $\mathrm{O}_{2}$ (Table 2). The results show that the functionalization itself induces a decrease of the catalyst content, of the same magnitude as the purification step ( $4 \mathrm{wt}$.\% lower than pristine SWCNT).

Wide scan XPS spectra of pristine, purified, f-SWCNT, and h-SWCNT are shown in Figure 5a. The $\mathrm{N}$ 1s peak is present for all the f-SWCNT and h-SWCNT. A considerable increase of the O 1s peak intensity is observed relative to pristine SWCNT, increasing in the order: $\mathrm{S}<\mathrm{SP}<\mathrm{f}-\mathrm{SP} 1<\mathrm{f}-\mathrm{S} 1<\mathrm{f}-\mathrm{S} 6$. The presence of $\mathrm{Cu}$ and $\mathrm{Ag}$ is confirmed by the peaks centered at $933.40 \mathrm{eV}$ and $368.49 \mathrm{eV}$, respectively, for f-S1Cu and f-S1Ag, as shown in Figure 6.

The high-resolution $C 1 s$ spectra depicted in Figure $5 b$ for the untreated, purified, and functionalized SWCNT are characterized by a main component peak centered at $284.8 \mathrm{eV}$, assigned to the $\mathrm{sp}^{2} \mathrm{C}$ of the graphene-like SWCNT lattice, and a strong tailing towards the higher binding energy side. This tailing is due to the conjugation of the $\pi$-electrons in the polyaromatic SWCNT lattice, and complicates the $C 1$ s peak analysis. The deconvolution of the $C 1$ s spectra show the absence of component peaks above $288 \mathrm{eV}$ for S, SP, and f-SP1 nanotubes, while f-S1 and f-S6 show peaks at $288 \mathrm{eV}$ and above. The lower binding energy (BE) range $285-287.5 \mathrm{eV}$ may be assigned to $\mathrm{C}-\mathrm{O}$ and $\mathrm{C}-\mathrm{N}$ bonds (Ph-OH, Ph- $\mathrm{CH}_{2}-\mathrm{O}-, \mathrm{C}-\mathrm{N}-\mathrm{C}$, for example) while carbonyl in functional groups such as ester or amide $(\mathrm{O}=\mathrm{C}-\mathrm{O}-, \mathrm{O}=\mathrm{C}-\mathrm{NH})$ are associated to higher $\mathrm{BE}$, above $288 \mathrm{eV}$. Thus, pristine and purified SWCNT, as well as f-SP1 contain a sPLPmall contribution of carbonyl functional groups, while the surface composition of f-S1 and f-S6 contain a considerable concentration of this class of functional groups. Atomic percentages calculated for the peak components, as well as additional figures, can be found in the supplementary materials (Table S1, Figures S2 and S3). The deconvolution of the high-resolution N 1 s spectra yields two peaks centered at $400.5 \mathrm{eV}$ (corresponding to $>\mathrm{N}-\mathrm{COO}-$, as in benzyl carbamate) and $399.2 \mathrm{eV}$ (corresponding to $>\mathrm{NH}$, as in pyrrolidine) as represented in Figure $5 \mathrm{c}$. The ratio of $>\mathrm{NH}$ : $>\mathrm{N}-\mathrm{COO}-$ measured for the $\mathrm{f}-$ and h-SWCNT is listed in Table 3, showing that f-SP1, functionalized at higher temperature, contains equal composition of benzyl carbamate (1) and pyrrolidine (2) while the remaining $\mathrm{f}$ - and h-SWCNT, functionalized at lower temperature, present approximately $20 \%$ of the functional groups in pyrrolidine form. Table 4 shows that the $\mathrm{N}$ at $\%$ is relatively similar for SP5, f-S1, $\mathrm{f}-\mathrm{S} 1 \mathrm{Ag}$, and f-S1Cu, presenting similar N:C ratios (Table 3). Since the DCA reaction is the only source of $\mathrm{N}$, the $\mathrm{N}$ at $\%$ is a good indicator of the degree of organic functionalization reached. Conversely, the measured surface oxygen originates from different sources: the pristine and purified SWCNT contain oxygen, functionalized SWCNT contain oxygen associated to the $\mathrm{O}=\mathrm{C}-\mathrm{NH}$ in benzyl carbamate, and 
under oxidizing conditions, f-S1Ag and f-S1Cu contain oxygen compounds of inorganic origin (Cu or Ag oxides, traces of $\mathrm{Cu}$ or Ag salts), thus complicating the estimate of oxygen resulting from the DCA reaction alone.

(a)

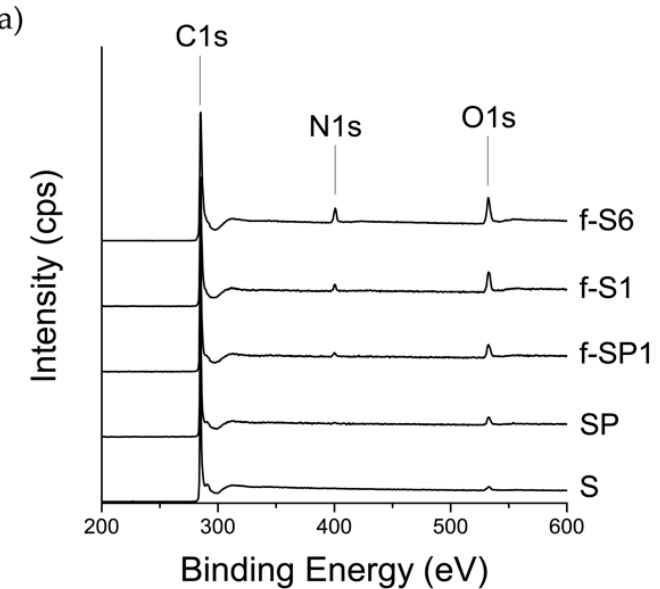

(c)
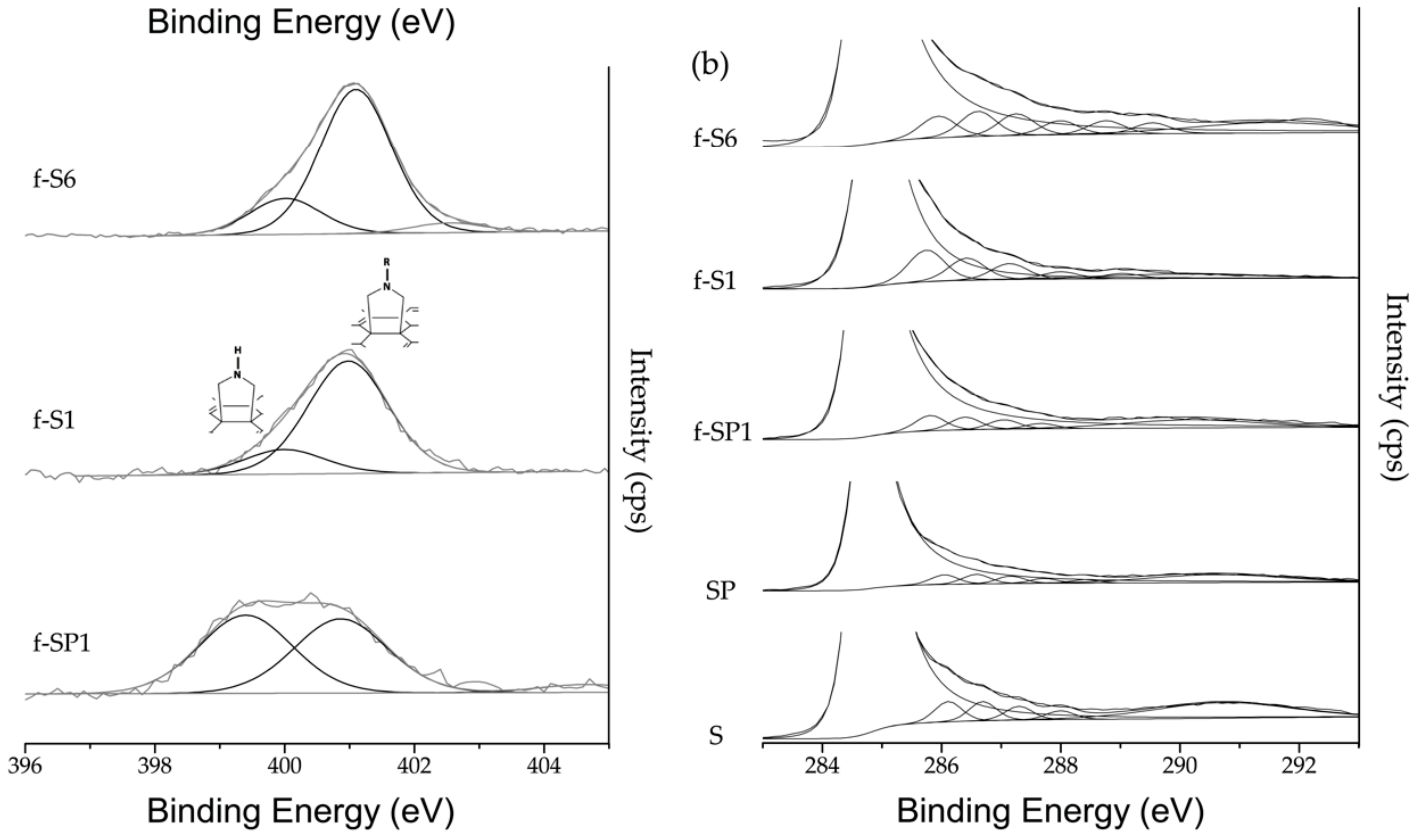

Figure 5. (a) Wide scan X-ray photoelectron spectroscopy (XPS) spectra of pristine, purified, and f-SWCNT; deconvolution of high resolution XPS spectra of (b) C 1s peak of f-SWCNT, purified, and pristine SWCNT; and (c) N 1s of f-SWCNT.

Table 3. Fraction of $\mathrm{N}$ at $\%$ relative to $\mathrm{C}$ and $\mathrm{O}$, and the ratio $>\mathrm{NH}$ : $>\mathrm{NR}$ (pyrrolidine group to benzyl carbamate group) as measured by XPS.

\begin{tabular}{rccc}
\hline & N:C & N:Oorg & $>$ NH:>NR \\
\hline f-SP1 & 0.02 & 2.36 & 1.05 \\
f-S1 & 0.02 & 0.43 & 0.17 \\
f-S1Ag & 0.02 & 0.34 & 0.19 \\
f-S1Cu & 0.02 & 0.28 & 0.25 \\
f-S6 & 0.05 & 0.89 & 0.25 \\
\hline
\end{tabular}



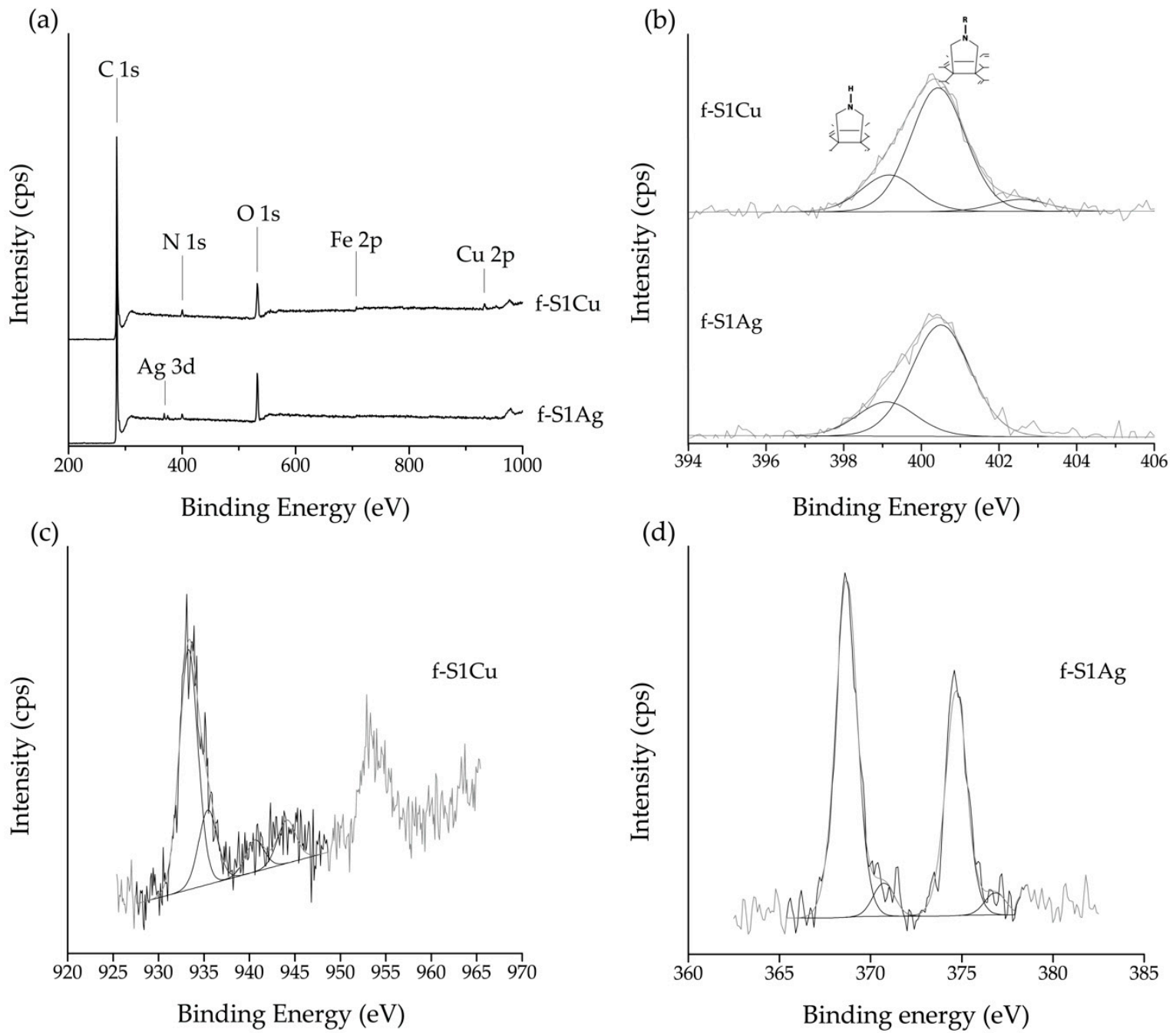

Figure 6. (a) Wide scan XPS spectra of h-SWCNT; deconvolution of high resolution XPS spectra of h-SWCNT (b) N 1s peak; (c) Cu 2p peak of f-S1Cu; and (d) Ag 3d peak of f-S1Ag.

Table 4. Atomic percentages of the elements present in each sample, as obtained by XPS.

\begin{tabular}{ccccccc}
\hline & \multicolumn{7}{c}{ Atomic \% } \\
\cline { 2 - 7 } & C 1s & N 1s & (O 1s) org $^{\mathbf{1}}$ & Ag 3d & Cu 2p & Fe 2p \\
\hline S & 97.79 & - & 1.30 & - & - & 0.64 \\
SP & 96.55 & - & 3.2 & - & - & 0.25 \\
f-SP1 & 94.78 & 1.57 & 0.67 & - & - & - \\
f-S1 & 91.2 & 2.13 & 4.93 & - & - & 0.12 \\
f-S1Ag & 90.36 & 1.67 & 4.90 & 0.09 & - & 0.11 \\
f-S1Cu & 92.03 & 1.4 & 5.09 & - & 0.08 & 0.13 \\
f-S6 & 88.32 & 4.52 & 5.08 & - & - & 0.58 \\
\hline
\end{tabular}

${ }^{1}$ Atomic $\%$ corrected accounting for the oxygen bonded to traces of $\mathrm{Si}$.

Evidence for the presence of $\mathrm{Ag}$ and $\mathrm{Cu}$ on h-SWCNT is provided by the wide scan XPS spectra (Figure 6a). High resolution spectra of $\mathrm{N} 1 \mathrm{~s}$ for f-S1Ag and f-S1Cu are similar to those observed for f-S1 (Figure 6b), however slightly shifted to lower eV. The Ag 3d high resolution XPS spectrum of f-S1Ag (Figure 6d) shows the characteristic peaks of the Ag metallic form (BE $368.6 \mathrm{eV}$ for $3 \mathrm{~d}_{5 / 2}$ and $374.6 \pm$ $0.07 \mathrm{eV}$ for $3 \mathrm{~d}_{3 / 2}$ [54]) thus indicating that the reduction of the Ag salt was effective. Nanosized Ag dots are observed at the surface of the pristine SWCNT and, at much higher concentration, on the surface 
of the f-SWCNT (Figure 3 and Figure S1). High resolution spectra of $\mathrm{Cu} 2 \mathrm{p}$ presents an asymmetric $2 \mathrm{p}_{3 / 2}$ peak near $933.3 \mathrm{eV}$ which may be assigned to $\mathrm{Cu}(\mathrm{I})$.species, indicating a partial reduction of $\mathrm{Cu}\left(\mathrm{CH}_{3} \mathrm{COOH}\right)_{2}[54,55]$.

\subsection{Single Walled Carbon Nanotube Structure and Functionalization}

Raman spectroscopy is a non-destructive technique that analyses the inelastic scattering of light and has been widely used to characterize graphitic materials. The Raman spectrum of SWCNT is characterized by two first-order modes, the $G$ band at $\sim 1580 \mathrm{~cm}^{-1}$, split into several shoulders, and the RBM in the frequency range of $100-500 \mathrm{~cm}^{-1}$, with frequency that is inversely proportional to the tube diameter [53]. The Raman mode D $\left(\sim 1350 \mathrm{~cm}^{-1}\right)$ is sensitive to defects in the $\mathrm{sp}^{2}$ carbon lattice while 2D band $\left(\sim 2670 \mathrm{~cm}^{-1}\right)$, with two times the frequency of D band, results from resonance effects [56].

Raman spectra of pristine, purified, f-SWCNT, and h-SWCNT are presented in Figure 7. The RBM region depicted in Figure 7a shows changes in frequency induced by chemical functionalization. These changes are observed across the whole RBM frequency range with no clear evidence for preferential functionalization of SWCNT with specific chirality. The RBM modes continue to be active for the functionalized SWCNT, they do not disappear as reported for oxidized SWCNT [57] denoting that the nanotube structure was not damaged. Additional data included as supplementary material allowed a rough estimate of the SWCNT diameter, showing a similar diameter range for as received and functionalized SWCNT (Figure S4 and Table S2). Figure 7b presents the D and G bands of f-SWCNT and h-SWCNT illustrating their similarity to the pristine and purified SWCNT in terms of intensity and area. A small increase in the intensity of the D band is observed for samples f-S6 and f-S1, confirming that the functionalization did not induce extensive damage. A downshift of $\sim 4 \mathrm{~cm}^{-1}$ is observed for the 2D band for both types of h-SWCNT (Figure 7c) which may be induced by charge transfer between SWCNT and the metal anchored at the SWCNT surface [58].

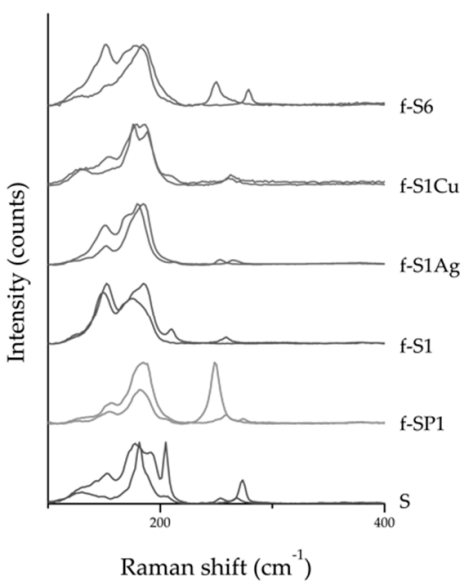

(a)

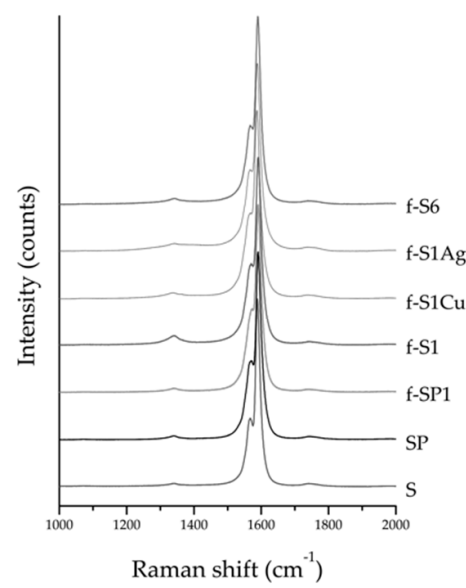

(b)

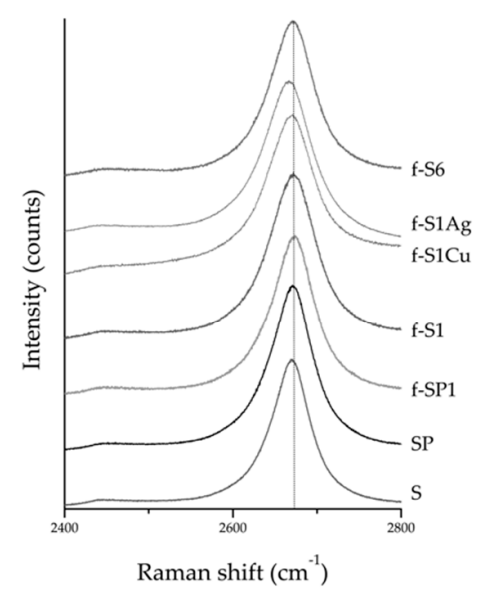

(c)

Figure 7. (a) radial breathing mode (RBM), (b) D, G, and (c) 2D Raman peaks of pristine, purified, f-SWCNT, and h-SWCNT.

\section{Conclusions}

A simple one-pot and solvent-free method based on the 1,3-dipolar cycloaddition reaction of azomethine ylides was implemented for the functionalization of SWCNT. The reaction yield, in terms of functional groups bonded to the SWCNT, was observed to vary with reagent concentration, while an increase in the reaction temperature resulted in further cleavage of the protecting group in the pyrrolidine nitrogen without decrease of functional group concentration.

XPS analysis showed that the reduction of $\mathrm{AgNO}_{3}$ in the presence of SWCNT and f-SWCNT in DMF was effective, yielding metallic Ag NP at the nanotube surface. A similar procedure was 
tested for the reduction of $\mathrm{Cu}\left(\mathrm{CH}_{3} \mathrm{COO}\right)_{2}$ however, under the reaction conditions tested, only partial reduction was achieved for the organic Cu salt. A higher yield of Ag NP was observed for the f-SWCNT compared to the pristine SWCNT, indicating that the functionalization plays a role in the formation and stabilization of Ag NP at the SWCNT surface. Raman spectroscopy demonstrated the structural quality of the SWCNT before and after functionalization, while showing changes in the RBM region that may be related to functionalization selectivity and may be interesting to study further. The $2 \mathrm{D}$ band of the h-SWCNT presented a small downshift relative to SWCNT and f-SWCNT that may relate to charge transfer with the NP anchored at the SWCNT surface.

Supplementary Materials: The following are available online at http://www.mdpi.com/2079-4991/9/10/1416/s1, Figure S1: (a) SEM image of single walled carbon nanotubes (SWCNT) f-S1_Ag; images of the distribution of (b) Fe nanoparticles; and (c) Ag nanoparticles, as obtained by energy dispersive spectroscopy (EDS) mapping, Table S1: Atomic percentages of the deconvoluted peaks of C 1s high resolution X-ray photoelectron spectroscopy (XPS) spectra, Figure S2: High resolution XPS spectra of C 1s peaks of (a) purified samples before and after functionalization and as-received SWCNT; (b) non-purified samples of functionalized and as-received SWCNT, Figure S3: Deconvolution of high resolution XPS spectra of C 1s peaks of the amine-functionalized SWCNT, Figure S4: Radial breathing mode (RBM) peaks for the amine functionalized and as-received SWCNT at laser energy of (a) $2.33 \mathrm{eV}$; (b) $1.96 \mathrm{eV}$; and (c) $1.58 \mathrm{eV}$, Table S2: Estimated diameters, at different laser excitation, for as-received and functionalized SWCNT.

Author Contributions: Conceptualization, M.C.P. and M.F.P.; methodology M.M.S., M.C.P. and E.C.; investigation, M.M.S. and D.R.; data curation M.M.S.; writing—original draft preparation, M.M.S.; writing—review and editing, M.C.P., M.F.P; R.J.Y.

Funding: This research was funded by the Portuguese Foundation for Science and Technology (FCT) for project PEst-C/CTM/LA0025/2013 (LA 25-2015-2018).

Acknowledgments: M.M.S. acknowledges the ERASMUS+ Program that allowed collaboration with Manchester University. M.M.S. is thankful to Elsa Oliveira and Paulo Lopes for the training and guidance provided at Universidade do Minho. The authors acknowledge the support of the Portuguese Foundation for Science and Technology through project Pest-C/CTM/LA0025/2013 (LA 25-2015-2018).

Conflicts of Interest: The authors declare no conflict of interest.

\section{References}

1. Lu, J.P. Elastic properties of single and multilayered nanotubes. J. Phys. Chem. Solids 1997, 58, 1649-1652. [CrossRef]

2. Yu, M.-F.; Files, B.S.; Arepalli, S.; Ruoff, R.S. Tensile Loading of Ropes of Single Wall Carbon Nanotubes and their Mechanical Properties. Phys. Rev. Lett. 2000, 84, 5552-5555. [CrossRef] [PubMed]

3. Hone, J.; Llaguno, M.; Biercuk, M.; Johnson, A.; Batlogg, B.; Benes, Z.; Fischer, J. Thermal properties of carbon nanotubes and nanotube-based materials. Appl. Phys. A 2002, 74, 339-343. [CrossRef]

4. Pop, E.; Mann, D.; Wang, Q.; Goodson, K.; Dai, H. Thermal Conductance of an Individual Single-Wall Carbon Nanotube above Room Temperature. Nano Lett. 2006, 6, 96-100. [CrossRef]

5. Berber, S.; Kwon, Y.-K.; Tománek, D. Unusually High Thermal Conductivity of Carbon Nanotubes. Phys. Rev. Lett. 2000, 84, 4613-4616. [CrossRef]

6. Ebbesen, T.W.; Lezec, H.J.; Hiura, H.; Bennett, J.W.; Ghaemi, H.F.; Thio, T. Electrical conductivity of individual carbon nanotubes. Nature 1996, 382, 54-56. [CrossRef]

7. Suzuki, S.; Bower, C.; Watanabe, Y.; Zhou, O. Work functions and valence band states of pristine and Cs-intercalated single-walled carbon nanotube bundles. Appl. Phys. Lett. 2000, 76, 4007-4009. [CrossRef]

8. Okazaki, K.; Nakato, Y.; Murakoshi, K. Absolute potential of the Fermi level of isolated single-walled carbon nanotubes. Phys. Rev. B 2003, 68, 035434. [CrossRef]

9. Javey, A.; Kim, H.; Brink, M.; Wang, Q.; Ural, A.; Guo, J.; McIntyre, P.; McEuen, P.; Lundstrom, M.; Dai, H. High-kappa dielectrics for advanced carbon-nanotube transistors and logic gates. Nat. Mater. 2002, 1, 241-246. [CrossRef]

10. Javey, A.; Guo, J.; Wang, Q.; Lundstrom, M.; Dai, H. Ballistic carbon nanotube field-effect transistors. Nature 2003, 424, 654-657. [CrossRef]

11. Wildoer, J.W.G.; Venema, L.C.; Rinzler, A.G.; Smalley, R.E.; Dekker, C. Electronic structure of atomically resolved carbon nanotubes. Nature 1998, 391, 59-62. [CrossRef] 
12. Iijima, S. Helical microtubules of graphitic carbon. Nature 1991, 354, 56-58. [CrossRef]

13. Yang, T.; Zhao, X.; Nagase, S. 1,3-Dipolar cycloadditions of Stone-Wales defective single-walled carbon nanotubes: A theoretical study. J. Comput. Chem. 2013, 34, 2223-2232. [CrossRef] [PubMed]

14. Srivastava, D.; Brenner, D.W.; Schall, J.D.; Ausman, K.D.; Yu, M.; Ruoff, R.S. Predictions of Enhanced Chemical Reactivity at Regions of Local Conformational Strain on Carbon Nanotubes: Kinky Chemistry. J. Phys. Chem. B 1999, 103, 4330-4337. [CrossRef]

15. Karousis, N.; Tagmatarchis, N.; Tasis, D. Current Progress on the Chemical Modification of Carbon Nanotubes. Chem. Rev. 2010, 110, 5366-5397. [CrossRef]

16. Balasubramanian, K.; Burghard, M. Chemically Functionalized Carbon Nanotubes. Small 2005, 1, $180-192$. [CrossRef]

17. Georgakilas, V.; Tagmatarchis, N.; Pantarotto, D.; Bianco, A.; Briand, J.-P.; Prato, M. Amino acid functionalisation of water soluble carbon nanotubes. Chem. Commun. 2002, 3050-3051. [CrossRef]

18. Kordatos, K.; Da Ros, T.; Bosi, S.; Vázquez, E.; Bergamin, M.; Cusan, C.; Pellarini, F.; Tomberli, V.; Baiti, B.; Pantarotto, D.; et al. Novel versatile fullerene synthons. J. Org. Chem. 2001, 66, 4915-4920. [CrossRef]

19. Georgakilas, V.; Kordatos, K.; Prato, M.; Guldi, D.M.; Holzinger, M.; Hirsch, A. Organic functionalization of carbon nanotubes. J. Am. Chem. Soc. 2002, 124, 760-761. [CrossRef]

20. Gonzalez-Dominguez, J.M.; Gonzalez, M.; Ansón-Casaos, A.; Díez-Pascual, A.M.; Gomez, M.A.; Martínez, M.T. Effect of Various Aminated Single-Walled Carbon Nanotubes on the Epoxy Cross-Linking Reactions. J. Phys. Chem. C 2011, 115, 7238-7248. [CrossRef]

21. Mulvey, J.J.; Feinberg, E.N.; Alidori, S.; McDevitt, M.R.; Heller, D.A.; Scheinberg, D.A. Synthesis, pharmacokinetics, and biological use of lysine-modified single-walled carbon nanotubes. Int. J. Nanomed. 2014, 9, 4245-4255.

22. García, A.; Herrero, M.A.; Frein, S.; Deschenaux, R.; Munoz, R.; Bustero, I.; Toma, F.; Prato, M. Synthesis of dendrimer-carbon nanotube conjugates. Phys. Status Solidi A Appl. Mater. Sci. 2008, 205, 1402-1407. [CrossRef]

23. Yao, Z.; Braidy, N.; Botton, G.A.; Adronov, A. Polymerization from the surface of single-walled carbon nanotubes-Preparation and characterization of nanocomposites. J. Am. Chem. Soc. 2003, 125, 16015-16024. [CrossRef] [PubMed]

24. Wang, Y.; Iqbal, Z.; Mitra, S. Microwave-induced rapid chemical functionalization of single-walled carbon nanotubes. Carbon 2005, 43, 1015-1020. [CrossRef]

25. Tagmatarchis, N.; Prato, M.; Guldi, D.M. Soluble carbon nanotube ensembles for light-induced electron transfer interactions. Phys. E Low Dimens. Syst. Nanostruct. 2005, 29, 546-550. [CrossRef]

26. Ondera, T.J.; Hamme, A.T. A gold nanopopcorn attached single-walled carbon nanotube hybrid for rapid detection and killing of bacteria. J. Mater. Chem. B 2014, 2, 7534-7543. [CrossRef]

27. Gaudino, E.C.; Tagliapietra, S.; Martina, K.; Barge, A.; Lolli, M.; Terreno, E.; Lembo, D.; Cravotto, G. A novel SWCNT platform bearing DOTA and beta-cyclodextrin units. "One shot" multidecoration under microwave irradiation. Org. Biomol. Chem. 2014, 12, 4708-4715. [CrossRef]

28. Paiva, M.C.; Novais, R.M.; Araujo, R.F.; Pederson, K.K.; Proenca, M.F.; Silva, C.J.R.; Costa, C.M.; Lanceros-Mendez, S. Organic Functionalization of Carbon Nanofibers for Composite Applications. Polym. Compos. 2010, 31, 369-376. [CrossRef]

29. Paiva, M.C.; Simon, F.; Novais, R.M.; Ferreira, T.; Proença, M.F.; Xu, W.; Besenbacher, F. Controlled Functionalization of Carbon Nanotubes by a Solvent-free Multicomponent Approach. ACS Nano 2010, 4, 7379-7386. [CrossRef]

30. Sahoo, S.; Husale, S.; Karna, S.; Nayak, S.K.; Ajayan, P.M. Controlled Assembly of Ag Nanoparticles and Carbon Nanotube Hybrid Structures for Biosensing. J. Am. Chem. Soc. 2011, 133, 4005-4009. [CrossRef]

31. Wang, T.; Kaempgen, M.; Nopphawan, P.; Wee, G.; Mhaisalkar, S.; Srinivasan, M. Silver nanoparticle-decorated carbon nanotubes as bifunctional gas-diffusion electrodes for zinc-air batteries. J. Power Sources 2010, 195, 4350-4355. [CrossRef]

32. Cvetićanin, J.; Krkljes, A.; Kačarević-Popović, Z.; Mitrić, M.; Rakočević, Z.; Trpkov, D.; Nešković, O. Functionalization of carbon nanotubes with silver clusters. Appl. Surf. Sci. 2010, 256, 7048-7055. [CrossRef]

33. Choi, S.K.; Chun, K.-Y.; Lee, S.-B. Selective decoration of silver nanoparticles on the defect sites of single-walled carbon nanotubes. Diam. Relat. Mater. 2009, 18, 637-641. [CrossRef] 
34. Paul, R.; Maity, A.; Mitra, A.; Kumbhakar, P.; Mitra, A.K. Synthesis and study of optical and electrical characteristics of a hybrid structure of single wall carbon nanotubes and silver nanoparticles. J. Nanopart. Res. 2011, 13, 5749-5757. [CrossRef]

35. Lin, Y.; Watson, K.A.; Fallbach, M.J.; Ghose, S.; Smith, J.G.; DeLozier, D.M.; Cao, W.; Crooks, R.E.; Connell, J.W. Rapid, Solventless, Bulk Preparation of Metal Nanoparticle-Decorated Carbon Nanotubes. ACS Nano 2009, 3, 871-884. [CrossRef]

36. Asad, M.; Sheikhi, M.H. Surface acoustic wave based H2S gas sensors incorporating sensitive layers of single wall carbon nanotubes decorated with Cu nanoparticles. Sens. Actuators B Chem. 2014, 198, 134-141. [CrossRef]

37. Seo, S.M.; Kang, T.J.; Cheon, J.H.; Kim, Y.H.; Park, Y.J. Facile and scalable fabrication of chemiresistive sensor array for hydrogen detection based on gold-nanoparticle decorated SWCNT network. Sens. Actuators B Chem. 2014, 204, 716-722. [CrossRef]

38. Pastoriza-Santos, I.; Liz-Marzán, L.M. Formation and Stabilization of Silver Nanoparticles through Reduction by N,N-Dimethylformamide. Langmuir 1999, 15, 948-951. [CrossRef]

39. Alimohammadi, F.; Gashti, M.P.; Shamei, A.; Kiumarsi, A. Deposition of silver nanoparticles on carbon nanotube by chemical reduction method: Evaluation of surface, thermal and optical properties. Superlattices Microstruct. 2012, 52, 50-62. [CrossRef]

40. Ma, P.C.; Tang, B.Z.; Kim, J.-K. Effect of CNT decoration with silver nanoparticles on electrical conductivity of CNT-polymer composites. Carbon 2008, 46, 1497-1505. [CrossRef]

41. Dutta, S.; Ray, C.; Sarkar, S.; Pradhan, M.; Negishi, Y.; Pal, T. Silver Nanoparticle Decorated Reduced Graphene Oxide (rGO) Nanosheet: A Platform for SERS Based Low-Level Detection of Uranyl Ion. ACS Appl. Mater. Interfaces 2013, 5, 8724-8732. [CrossRef] [PubMed]

42. Chun, K.-Y.; Oh, Y.; Rho, J.; Ahn, J.-H.; Kim, Y.-J.; Choi, H.R.; Baik, S. Highly conductive, printable and stretchable composite films of carbon nanotubes and silver. Nat. Nanotechnol. 2010, 5, 853-857. [CrossRef] [PubMed]

43. Espinosa, E.; Ionescu, R.; Bittencourt, C.; Felten, A.; Erni, R.; Van Tendeloo, G.; Pireaux, J.-J.; Llobet, E. Metal-decorated multi-wall carbon nanotubes for low temperature gas sensing. Thin Solid Films 2007, 515, 8322-8327. [CrossRef]

44. Yuan, W.; Jiang, G.; Che, J.; Qi, X.; Xu, R.; Chang, M.W.; Chen, Y.; Lim, S.Y.; Dai, J.; Chan-Park, M.B. Deposition of Silver Nanoparticles on Multiwalled Carbon Nanotubes Grafted with Hyperbranched Poly(amidoamine) and Their Antimicrobial Effects. J. Phys. Chem. C 2008, 112, 18754-18759. [CrossRef]

45. Tang, L.; Duan, F.; Chen, M. Silver nanoparticle decorated polyaniline/multiwalled super-short carbon nanotube nanocomposites for supercapacitor applications. RSC Adv. 2016, 6, 65012-65019. [CrossRef]

46. Di Bartolomeo, A.; Yang, Y.; Rinzan, M.B.M.; Boyd, A.K.; Barbara, P. Record Endurance for Single-Walled Carbon Nanotube-Based Memory Cell. Nanoscale Res. Lett. 2010, 5, 1852-1855. [CrossRef]

47. Odintsov, A.A. Schottky Barriers in Carbon Nanotube Heterojunctions. Phys. Rev. Lett. 2000, 85, 150-153. [CrossRef]

48. Tersoff, J. Nanotechnology-A barrier falls. Nature 2003, 424, 622-623. [CrossRef]

49. McAndrew, C.F.; Baxendale, M. High electrical conductance enhancement in Au-nanoparticle decorated sparse single-wall carbon nanotube networks. Nanotechnology 2013, 24, 305202. [CrossRef]

50. Chen, Y.-C.; Young, R.J.; MacPherson, J.V.; Wilson, N.R. Single-Walled Carbon Nanotube Networks Decorated with Silver Nanoparticles: A Novel Graded SERS Substrate. J. Phys. Chem. C 2007, 111, 16167-16173. [CrossRef]

51. Chen, Y.-C.; Young, R.; MacPherson, J.V.; Wilson, N. Silver-decorated carbon nanotube networks as SERS substrates. J. Raman Spectrosc. 2011, 42, 1255-1262. [CrossRef]

52. Wang, Y.H.; Shan, H.; Hauge, R.H.; Pasquali, M.; Smalley, R.E. A highly selective, one-pot purification method for single-walled carbon nanotubes. J. Phys. Chem. B 2007, 111, 1249-1252. [CrossRef] [PubMed]

53. Clancy, A.J.; White, E.R.; Tay, H.H.; Yau, H.C.; Shaffer, M.S. Systematic comparison of conventional and reductive single-walled carbon nanotube purifications. Carbon 2016, 108, 423-432. [CrossRef]

54. Moulder, J.F. Handbook of Photoelectron Spectroscopy; Physicical Electronics Division, Perkin-Elmer Corporation: Eden Prairie, MN, USA, 1992.

55. Biesinger, M.C. Advanced analysis of copper X-ray photoelectron spectra. Surf. Interface Anal. 2017, 49, 1325-1334. [CrossRef] 
56. Dresselhaus, M.; Dresselhaus, G.; Saito, R.; Jorio, A. Raman spectroscopy of carbon nanotubes. Phys. Rep. Rev. Sect. Phys. Lett. 2005, 409, 47-99. [CrossRef]

57. Hussain, S.; Jha, P.; Chouksey, A.; Raman, R.; Islam, S.; Choudhary, P. Spectroscopic Investigation of Modified Single Wall Carbon Nanotube (SWCNT). J. Mod. Phys. 2011, 2, 538-543. [CrossRef]

58. Dresselhaus, M.S.; Jorio, A.; Hofmann, M.; Dresselhaus, G.; Saito, R. Perspectives on Carbon Nanotubes and Graphene Raman Spectroscopy. Nano Lett. 2010, 10, 751-758. [CrossRef] 